\title{
Oral dexamethasone led to fewer treatment failures than did nebulised dexamethasone or placebo in children with mild croup
}

Luria JW,Gonzalez-del-Rey JA, DiGiulio GA, et al. Effectiveness of oral or nebulized dexamethasone for children with mild croup. Arch Pediatr Adolesc Med 2001 Dec;155:1340-5.

QUESTION: In children with mild croup, does oral dexamethasone decrease the need for subsequent treatments and care and shorten symptom duration more than nebulised dexamethasone or placebo?

\section{Design}

Randomised (allocation concealed*), blinded (patients, clinicians, outcome assessors, and data collectors $\} \nmid *$ placebo controlled trial with 7 days of follow up.

\section{Setting}

Emergency departments at 2 large urban tertiary care centres in Ohio, USA.

\section{Patients}

264 children between 6 months and 6 years of age (mean age 28 mo, 68\% boys) who had symptoms of croup for $<48$ hours. Exclusion criteria were severe disease, receipt of racemic epinephrine or corticosteroid treatment, spasmodic croup, or a history of prolonged endotracheal intubation or chronic respiratory illness. $84 \%$ of patients were assessed at day 7 .

\section{Intervention}

Children were allocated to oral dexamethasone, $0.6 \mathrm{mg} / \mathrm{kg}$ of body weight to a maximum dose of $10 \mathrm{mg}$, and nebulised placebo $(\mathrm{n}=85)$; nebulised dexamethasone sodium phosphate, $160 \mu \mathrm{g}(\mathrm{n}=91)$, and oral placebo; or oral and nebulised placebo $(\mathrm{n}=88)$.

\section{Main outcome measures}

The primary outcome was treatment failure (reevaluation leading to a prescription for corticosteroids or racemic epinephrine). Secondary outcomes were need for additional medical care and parental assessment of the child's condition.

\section{Main results}

Analysis was by intention to treat. Fewer children in the oral treatment group had treatment failure than did those in the nebulised treatment or placebo groups (table). Treatment failure did not differ between the nebulised treatment and placebo groups (table). Fewer children in the oral treatment group needed additional medical care than did those in the nebulised treatment and placebo groups $(13 \%$ v 33\% $v 37 \%$, respectively, $\mathrm{p}=0.002)$. Parents of children in the oral treatment group reported greater improvement in their child's condition at day 1 than did parents of children in the nebulised and placebo groups $(p<0.001)$. These results were not statistically different at days 2,3 , 4, or 7 .

\section{Conclusion}

In children with mild croup, oral dexamethasone led to fewer treatment failures, less need for additional medical care, and greater improvement in symptoms at 1 day than did nebulised dexamethasone or placebo.

*See glossary.

†Information provided by author.

Source of funding:

Bremer Foundation at

Ohio State University.

For correspondence:

Dr J Luria, Children's

Hospital Medical

Center, Cincinnati,

Ohio, USA.

joe.luria@chmcc.org.

Treatment failure of oral dexamethasone $(O D)$ v nebulised dexamethasone $(N D)$ or placebo in children with mild croup at 7 days:

\begin{tabular}{lllll} 
OD & ND & Placebo & RRR (95\% Cl) & NNT \\
$4 \%$ & - & $14 \%$ & $71 \%(6$ to 91$)$ & 11 (5 to 155$)$ \\
\hline $4 \%$ & $16 \%$ & - & $74 \%(17$ to 92$)$ & $9(5$ to 49$)$ \\
& & & RRI (Cl) & NNH \\
\hline & $16 \%$ & $14 \%$ & $11 \%(-48$ to 137$)$ & Not significant \\
\hline
\end{tabular}

‡Abbreviations defined in glossary; RRR, RRI, NNT, NNH, and $\mathrm{Cl}$ calculated from data in article.

\section{COMMENTARY}

Establishing croup as a steroid responsive disease has been one of the major advances in paediatric respiratory medicine in the previous 10 years. Both oral dexamethasone and nebulised budesonide are effective, relieving symptoms of croup as early as 6 hours after treatment. ${ }^{1}$ With the battle won, what remains are largely minor skirmishes, such as those addressed in the study by Luria et al. In this 3-way, randomised, placebo controlled trial, dexamethasone given orally is compared with nebulised dexamethasone in mild croup. The results reconfirm that oral dexamethasone $(0.6 \mathrm{mg} / \mathrm{kg})$ is effective with a number needed to treat of 11 , similar to that previously reported in a metaanalysis. ${ }^{1}$ Interestingly, and unlike the meta-analysis, nebulised steroid was no better than placebo. This finding probably occurred because (as Luria et al discuss) the nebulised dose was far too low $(160 \mu \mathrm{g}$, which is equivalent to 2 puffs from a dexamethasone metered dose inhaler).

Two points are worth noting. First, the oral dose used $(0.6 \mathrm{mg} / \mathrm{kg})$ is higher than necessary for effective treatment of mild croup. ${ }^{2}$ Second, Luria et al include no data on parent preference, nor do they include any analysis of cost benefit. In fact, as the authors comment, oral treatment is probably substantially cheaper and more convenient.

Some interesting questions remain. Dexamethasone is a particularly potent steroid. Are less potent steroids, like prednisolone, which is commonly used in asthma, as effective as dexamethasone? In more severe croup, is a combination of oral and nebulised drugs more effective? In the meantime, the message is clear: oral dexamethasone remains the knockout winner for the treatment of croup.

$$
\begin{array}{r}
\text { James Y Paton } \\
\text { Royal Hospital for Sick Children } \\
\text { Glasgow, Scotland, UK }
\end{array}
$$

1 Ausejo M, Saenz A, Pham B, et al. Glucocorticoids for croup. Cochrane Database Syst Rev 2002;(1):CD001955.

2 Geelhoed GC, Macdonald WB. Oral dexamethasone in the treatment of croup: 0.15 $\mathrm{mg} / \mathrm{kg}$ versus $0.3 \mathrm{mg} / \mathrm{kg}$ versus $0.6 \mathrm{mg} / \mathrm{kg}$. Pediatric Pulmonology 1995;20:362-8. 